\title{
Spinal corpora amylacea and motor neuron disease: a quantitative study
}

\author{
J B Cavanagh
}

\begin{abstract}
Objective-To test the hypothesis that as there is growing evidence that corpora amylacea, or amyloid bodies, in the CNS are derived primarily from neurons, it might be expected that their numbers in the spinal cord would decline with loss of neurons in motor neuron degeneration as they do in the retina on destruction of ganglion cells by glaucoma.
\end{abstract}

Methods-The numbers of corpora amylacea were counted in PAS stained transverse sections of the lumbar cord from 27 patients with motor neuron disease and 21 control subjects of similar age and sex mix. The numbers and sizes of corpora amylacea were determined both in the anterior horn grey matter and in the submeningeal white matter regions in each case.

Results-In both groups the total numbers in the white matter and submeningeal regions ranged from 160 to more than $5000 /$ section and there was minimal significant difference between the two groups. No relation with age was found in this narrow age range. The mean diameters of the corpora amylacea were significantly less in the grey matter of both groups than in the submeningeal regions. However, their densities in the grey matter of the anterior horn were significantly reduced in the spinal cord sections in the motor neuron disease group, but only where few motor neurons remained.

Conclusions-These findings support the view that corpora amylacea may arise from neurons, and suggest that that there may be two compartments, one mobile and one static, the second most likely remaining in the periphery of the spinal cord for prolonged periods.

(F Neurol Neurosurg Psychiatry 1998;65:488-491)

Keywords: corpora amylacea, polyglucosan bodies, spinal cord, motor neuron disease

Human corpora amylacea, first seen by

Department of Clinical Neurosciences, Institute of Psychiatry and King's College School of Medicine and Dentistry, London SE5 8AF, UK

J B Cavanagh

Received 9 February 1998 and in revised form

15 April 1998

Accepted 23 April 1998 are found in brain tissue beneath the pia mater and the ventricular ependyma where they seem to be largely within astrocyte processes. ${ }^{9}$ Supporting the concept of their origin from neurons, Kubota et $a l^{10}$ have found that, in eyes taken from patients with glaucoma, loss of neurons in the ganglion cell layer was associated with greatly reduced numbers of corpora amylacea. The present study was undertaken to seek confirmation of this finding in the lumbar spinal cords of cases of motor neuron disease where there was often severe depletion of neurons.

\section{Materials and methods}

Transverse sections of lumbar spinal cord (7 $\mu \mathrm{m}$ thick) were stained with McManusHotchkiss periodic acid-Schiff reagent after diastase treatment. This stains corpora amylacea a brilliant scarlet so that even the smallest is readily visible. The tissues came from 27 randomly selected patients with motor neuron disease, aged 46 to 84 years, who had an average survival from initial diagnosis of 25 months. All cases showed some evidence of upper motor neuron degeneration and were from the Motor Neuron Disease Association's Brain Bank maintained in the Department of Neuropathology at the Institute of Psychiatry. Also, 21 control cases were obtained from the same source comprising both non-relevant neurological and non-neurological cases with a similar age range and sex mix to the cases of motor neuron disease. The neurological control patients mainly had had acute disease and none showed any abnormalities in the spinal cord.

\section{COUNTING METHODS}

Corpora amylacea in the spinal cord lie mainly either beneath the pia mater in the peripheral white matter or in the grey matter of the anterior horns. There are a few, usually small, bodies in the posterior horns, but for the purpose of this study these were ignored. Total counts of corpora amylacea in the white matter and subpial regions were made all round the cord. For simplicity, this was done using an oblong ocular frame and a $\times 10$ objective; each sector of the cord was counted separately and the total was expressed as counts/section. At this magnification in well stained preparations bodies measuring down to $2 \mu \mathrm{m}$ in diameter were readily seen. The density of corpora amylacea in the anterior horns was assessed using a $\times 25$ objective with a $\times 10$ ocular, by counting all bodies within an oblong ocular frame measuring $340 \mu \mathrm{m} \times 220 \mu \mathrm{m}$. This frame could be placed 10 times over the grey matter of both 
Table 1 Peripheral (subpial) corpora amylacea

\begin{tabular}{llll}
\hline Total counts/section & Mean & (SD) & Range \\
\hline Control cases $(\mathrm{n}=21)$ & 1279.8 & $(1324.9)$ & $161-5470$ \\
MND cases $(\mathrm{n}=27)$ & 2065.5 & $(1704.9)$ & $127-5640$ \\
\hline
\end{tabular}

$\mathrm{p}>0.05 . \mathrm{MND}=$ motor neuron disease.

Table 2 Densities of corpora amylacea in anterior horn grey matter

\begin{tabular}{lcl}
\hline & Mean/mm & (SD) \\
\hline Control cases(n=21) & 277.2 & 261.3 \\
All MND cases $(\mathrm{n}=27)$ & 124.8 & $135.9^{\star}$ \\
MND group I cases $(\mathrm{n}=4)$ & 409.4 & $133.2^{\star}$ \\
MND group II cases (n=23) & 75.3 & $46.1^{\star \star}$ \\
\hline
\end{tabular}

${ }^{\star} \mathrm{p}=0.01 ;{ }^{\star \star} \mathrm{p}=0.001$.

Group I cases had moderate numbers of surviving anterior horn cells in the sections (see text).

Group II cases had few or no surviving anterior horn cells in the sections (see text). $\mathrm{MND}=$ motor neuron disease.

sides without overlapping. The number $/ \mathrm{mm}^{2}$ was then derived and the data were entered into a Microsoft Excel programme with which statistical computations were made. Student's $t$ test was used to compare numerical data.

\section{ASSESSING NEURON POPULATIONS}

For assessment of the numbers and health status of the neurons in the sections of the cases with motor neuron disease they were put into

Table 3 Measurements of diameters of corpora amylacea (100 measured in each location)

\begin{tabular}{|c|c|c|c|c|}
\hline & \multicolumn{2}{|l|}{ In posterior columns } & \multicolumn{2}{|c|}{ In anterior horn grey matter } \\
\hline & Means $(\mu m)(S D)$ & Range $(\mu \mathrm{m})$ & Means ( $\mu m)(S D)$ & Range $(\mu m)$ \\
\hline Control cases $(n=8)$ & $10.5(2.1)$ & $7.2-14.3$ & $5.7^{\star \star}(1.2)$ & $4.2-7.6$ \\
\hline MND cases $(n=9)$ & $10.8(1.3)$ & $8.4-13.0$ & $6.6^{\star \star}(1.4)$ & $4.8-8.3$ \\
\hline
\end{tabular}

${ }^{\star} \mathrm{p}<0.001 . \mathrm{MND}=$ motor neuron disease.
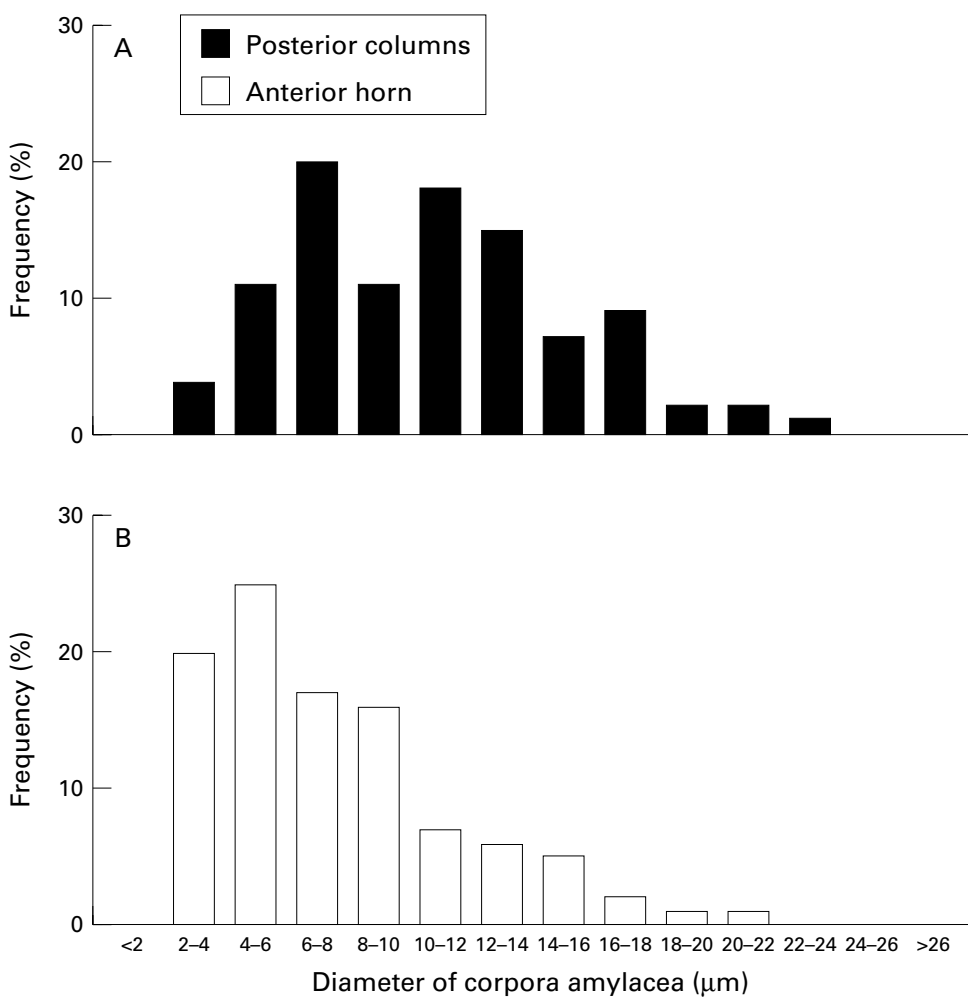

Figure 1 (A) Sample from control cases of size distribution of corpora amylacea in posterior columns (total number/section 3625), and (B) in the same anterior horn grey matter (density 304.8/ $\mathrm{mm}^{2}$ ). two groups: group I comprised those sections with several large unshrunken neurons in the section, sometimes approaching the population in control sections, and few clusters of lipofuscin debris (four cases); group II comprised those sections with only one to three small shrunken neurons with many clusters of lipofuscin debris (23 cases).

MEASUREMENT OF SIZES OF THE BODIES

Diameters of the corpora amylacea were assessed in eight control cases and in nine cases with motor neuron disease, chosen at random, with a movable ocular scale and a $\times 40$ objective: for each case 100 bodies were separately measured in each region.

\section{Results}

TOTAL NUMBERS OF CORPORA AMYLACEA IN THE

SPINAL CORD PERIPHERY

Table 1 shows that total numbers counted were remarkably variable in both groups and ranged from 161 to 5470/section (mean 1279.8) in controls and from 127 to 5640 /section (mean 2065.5) in the motor neuron disease group $(0.01<\mathrm{p}<0.05)$. No relation to age, sex, or clinical condition was apparent in either group, nor was any relation found between total numbers of peripheral corpora and abundance or otherwise of neurons in the anterior horns in the cases of motor neuron disease. Nothing could be found to account for the remarkable range of 30-fold to 40 -fold variation between the lowest to the highest counts. Although there was some variation in circumference of the spinal cord from one case to another, and this was probably more true for the cases of motor neuron disease, this difference might be just visible to the eye but could not have accounted for the great variability in the counts of corpora amylacea within both control and motor neuron disease groups.

DENSITIES OF CORPORA AMYLACEA IN ANTERIOR HORN GREY MATTER

Table 2 shows that the mean density of corpora $\left(277.2 / \mathrm{mm}^{2}\right)$ in sections from the control group was about twice the mean density for the motor neuron disease group $\left(124.8 / \mathrm{mm}^{2}\right.$; $\mathrm{p}=0.01)$. To relate this more closely to numbers of neurons, those cases in which moderate numbers of neurons were still present (group I; four cases) showed mean density somewhat greater than controls (409.4/ $\mathrm{mm}^{2} ; \mathrm{p}>0.05 \mathrm{NS}$ ). In the remaining 23 cases with very few or no remaining neurons (group II) the corpora amylacea were markedly less numerous than in controls $\left(75.3 / \mathrm{mm}^{2}\right.$; $\mathrm{p}=0.001)$.

SIZES OF CORPORA AMYLACEA IN SUBPIAL WHITE MATTER AND IN ANTERIOR HORN GREY MATTER Table 3 shows that there was very little difference between the mean diameters of corpora amylacea lying peripherally in eight control cases and nine cases of motor neuron disease, the ranges varied little and no special variation was found with total numbers counted/section. In the anterior horn grey matter, however, in both controls and cases 

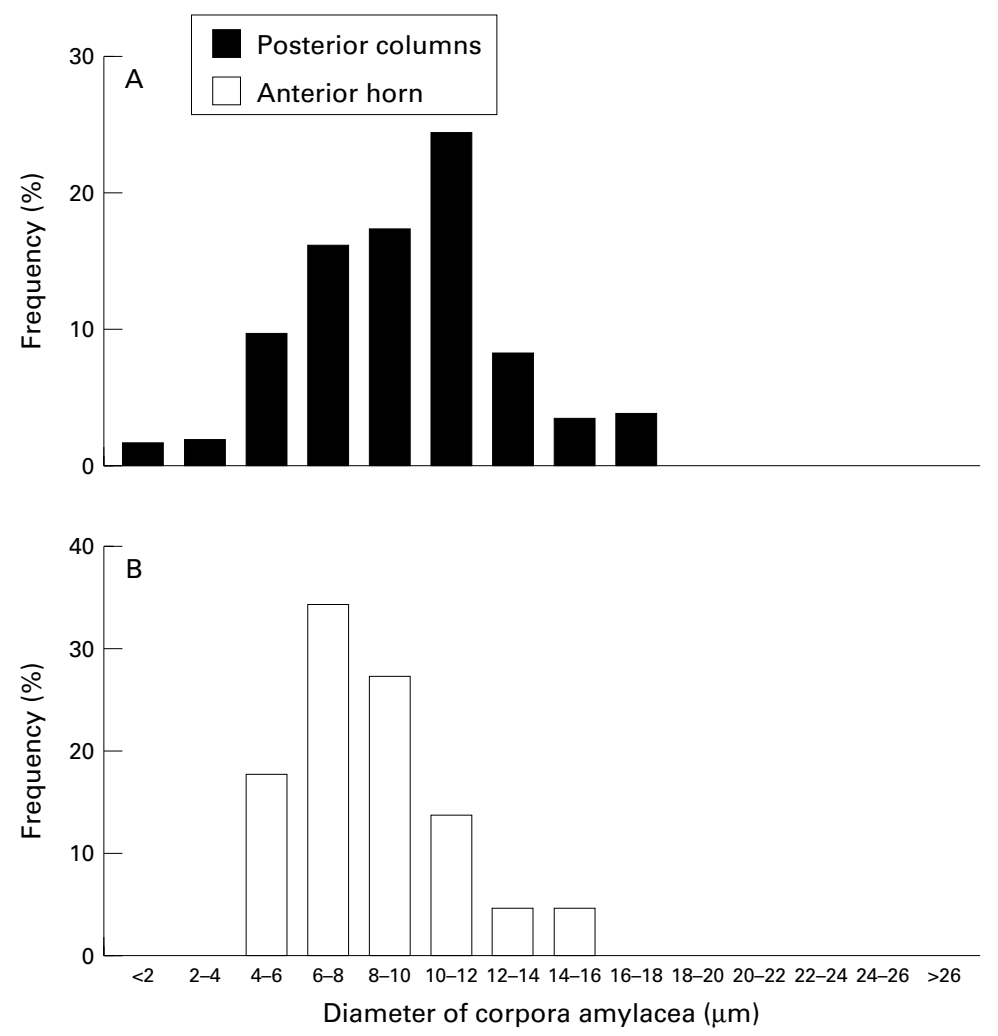

Figure 2 (A) Sample from cases of motor neuron disease, of size distribution of corpora amylacea in posterior columns (total number/section 3518), and (B) in the same anterior horn grey matter (density $58.2 / \mathrm{mm}^{2}$ ). Note the relative lack of small diameter bodies in the latter by comparison with fig $1 \mathrm{~B}$.

with motor neuron disease the mean diameters of bodies, although closely similar to one another, were significantly smaller than those lying peripherally (figs 1 and 2) It is noteworthy that there was a normal size distribution in the peripherally lying bodies of both controls and cases of motor neuron disease suggesting a settled population, whereas the size distributions in the grey matter in each were distinctly skewed to the right suggesting progressive formation and growth of the bodies.

\section{Discussion}

From this small study it is apparent that whereas the total number of corpora amylacea (polyglucosan bodies) lying in the periphery of the spinal cord was largely unaffected by loss of neurons in motor neuron disease, those lying in the grey matter of the anterior horns were greatly depleted commensurate with neuron loss. Moreover, not only was the density $/ \mathrm{mm}^{2}$ reduced, but small bodies $<4 \mu \mathrm{m}$ in diameter were notably depleted. There seems, thus, to be two separate compartments, a static peripheral one that was unaffected by changes in the neuronal population and a central mobile one the population of which changed in response to neuronal loss.

There is increasing evidence for the concept that many corpora amylacea in the CNS arise within neurons. Whereas larger bodies $>5 \mu \mathrm{m}$ in diameter occur within the processes of astrocytes, ${ }^{69}$ those less than this size have been seen principally within neurites ${ }^{67}$ and can be found at various points along both central and peripheral axons down to preterminal and terminal regions. ${ }^{7811}$ Although commonly found in neurites in humans and in other species ${ }^{12}$ they have rarely, if ever, been seen within the perikarya of neurons. Only in Lafora body disease, ${ }^{13}$ and in the related Bielschowsky body disease, ${ }^{14}$ in which polyglucosan bodies occur in abnormal numbers in younger age groups are they regularly, and characteristically, found in neuronal perikarya. In the human eye and optic nerve they invariably occur within neurites and in the retina there is a significant relation between size and position. Thus, they are smallest (3-6 $\mu \mathrm{m}$ in diameter) in the inner granular and plexiform layers, slightly larger in the ganglion cell layer, and largest in the nerve fibre layer and in the optic nerve $(8-10 \mu \mathrm{m}$ in diameter). ${ }^{1015}$ Furthermore, several authors have found that corpora amylacea in the cortex are smaller than those lying beneath the pia mater or ependyma. In the pia mater and ependyma they have an average diameter of $10-11 \mu \mathrm{m}$ and range up to $20 \mu \mathrm{m}$ or slightly more.

Because they increase in numbers with age, being uncommon below 30 years of age and become increasingly numerous after the age of 50 , if they are formed within neurons they must transfer to glial cells where the larger ones are commonly found. There are plenty of findings from experimental animals to indicate that cell to cell transfer of bulky materials is not only feasible but probably occurs regularly, particularly in stressful situations such as disease, injury or intoxication. ${ }^{16-23}$ This has not been shown specifically to take place with corpora amylacea, and it is not known whether there is a size limit to such transfers, but there is little doubt that mechanisms are available to effect this transfer.

It is thus probable that the relative preponderance of small forms in the grey matter reflects either their recent formation before being passed, as suggested, to astroglial processes for onward transit to the periphery, or their accumulation in preterminal and terminal neurites from elsewhere. In the special case of the retina, if they were formed within neurites it is not surprising that Kubota et $a l^{10}{ }^{15}$ found that the numbers of corpora amylacea gradually declined in parallel with the numbers of surviving ganglion cells with increasing severity of glaucoma, as measured by optic cup depth. The present findings add further evidence for a neuronal origin of corpora amylacea, and is in keeping with the immunocytochemical evidence indicating that they contain proteins and other materials, principally found in neurons, such as tau, ${ }^{324}$ extracytoplasmic domain of amyloid precursor protein, ${ }^{25}$ haemoxygenase- $1,{ }^{26}$ serum carnosinase, a neuronal GABA releasing enzyme, ${ }^{27}$ heat shock protein-72, ${ }^{28}$ and ubiquitin. ${ }^{4}$ But they also show evidence of other materials-namely, myelin basic protein, proteolipid protein, oligodendrocyte glycoprotein, and ferritin, ${ }^{5}$ that must be derived from oligodendrocytes suggesting that if corpora amylacea are not formed within these cells, and there is little evidence for this, astroglia probably play a part in incor- 
porating these into the bodies. This might be a natural route as there is strong evidence for the origin of polyglucosan bodies also in astrocytes which may well be the main source of those in the subpial and subependymal regions. ${ }^{29}$

The absence of any apparent response of total numbers of peripherally lying bodies to the loss of neurons from the spinal cords of cases of motor neuron disease is interesting as the process of neuron depletion must have been in progress in these cases at least since initial diagnosis-namely, for an average in these cases of 25 months, and their overall numbers were little affected during that time. The failure of their numbers to become depleted during such a relatively prolonged period, suggests that there may not normally be a significant steady loss of bodies from the pial surface to the CSF in the spinal cord despite the presence of many in the subpial spaces. However, this does contrast with the finding by Kubota $e t a l^{10}$ of complete loss of corpora amylacea from the optic nerve after glaucoma, which raises the question as to whether they in fact regularly "escape" from subpial regions. Sbarbati et $a l^{6}$ have shown them apparently being released into the subpial space, but whether this is a regular route is not known. If they are not, it might be concluded that accumulation of corpora amylacea at various sites within the CNS is a means whereby potentially damaging waste materials they seem to be containing ${ }^{26}$ may be harmlessly sequestered. Thus, the polyglucosan system may, perhaps, be looked on as analogous to the lysosomal-lipofuscin system for the removal of waste materials from highly metabolically active cells. It is of interest that the heart, another very metabolically active tissue, also shows accumulations of analogous bodies with age, so called "basophil or mucoid degeneration", ${ }^{30}$ with similar staining and immunochemical characteristics. The polyglucosan disorders-namely, Lafora body disease, Bielschowsky body disease, and adult polyglucosan body disease, the first and the last having strong hereditary (recessive) influences, could thus be considered as manifestations of a breakdown of this system and thus analogous in some ways to lysosomal storage diseases.

I am grateful to Professor PN Leigh for hospitality in his department, to Mrs VER Anderson for the preparation of the stained sections, and to the Department of Neuropathology for access to the Motor Neuron Disease Association's Tissue Bank. access to the Motor Neuron Disease Association's Tissue Bank.
Professor S Love of Bristol University, Dr DMA Mann of ManProfessor S Love of Bristol University, Dr DMA Mann of Man-
chester University, and Professor TW Bouldin of the University of North Carolina made very helpful comments that were of North Carolina
greatly appreciated.

1 Purkinje JE. Bericht über die Naturforscherversammlung zu Prag im fahre 1837 (cited by Catola G, Achúcarro N. Uber die Enstehung de Amyloidkörperchen in Zentralnervensysdie Enstehung de Amyloidkörperchen in Zentralnervensystem. Virchow's Archiv für Pathologisch Anatomie und

2 Buzzard EF, Greenfield JG. Pathology of the nervous system. London: Constable, 1921.
3 Loeffler KU, Edward DP, Tso MOM. Tau-2 immunoreactivity of corpora amylacea in the human retina and optic nerve. Invest Ophthalmol Vis Sci 1993;34:2600-01.

4 Cissé S, Perry G, Lacoste-Royal G, et al. Immunochemical identification of ubiquitin and heat-shock proteins in corpora amylacea from normal aged and Alzheimer's disease brains. Acta Neuropathol 1993; 85:233-40.

5 Singhrao SK, Neal JW, Piddlesden SJ, et al. New immunocytochemical evidence for a neuronal/ oligodendroglial origin for corpora amylacea. Neuropathol Appl Neurobiol 1994;20:66-3.

6 Anzil AP, Herrlinger $\mathrm{H}$, Blinzinger $\mathrm{K}$, et al. Intraneuritic corpora amylacea. Virchow's Archiv A Pathological Anatomy and Histopathology 1974;364:297-301.

7 Takahashi K, Agari M, Nakamura H. Intra-axonal corpora amylacea in ventral and lateral horns of the spinal cord. Acta Neuropathol 1975;11:151-8.

8 Averback P, Langevin $\mathrm{H}$. Corpora amylacea of the lumbar spinal cord and peripheral nervous system. Arch Neurol 1978;35:95-6.

9 Sbarbati A, Carner M, Colletti V, et al. Extrusion of corpora amylacea from the marginal glia at the vestibular root entry zone. F Neuropathol Exp Neurol 1996;55:196-201.

10 Kubota T, Naumann GOH. Reduction in number of corpora amylacea with advancing histological changes of glaucoma. Graefes Arch Clin Exp Ophthalmol1993;231:249-53.

11 Averback P. Parasynaptic corpora amylacea in the striatum. Arch Pathol 1981;105:334-5.

12 Suzuki Y, Ohta K, Kamya S, et al. Topographic distribution patterns of Lafora-like bodies in the spinal cord of some animals. Acta Neuropathol 1980;49:2159-61.

13 Schwarz GA, Yanoff M. Lafora's disease. Arch Neurol 1965;32:172-88.

14 Probst A, Sandoz P, Vanoni C, et al. Intraneuronal polyglucosan storage restricted to the lateral pallidum (Bielschowsky bodies). A Golgi, light- and electronmicroscopic study. Acta Neuropathol 1980;51:119-26.

15 Kubota T, Holbach LM, Naumann GOH. Corpora amylacea in glaucomatous and non-glaucomatous optic nerve and retina. Graefes Arch Clin Exp Ophthalmol 1993;231:7-11.

16 Gray EG, The fine structure of nerve. Comp Biochem Physiol (A) $1970 ; 36: 419-48$.

17 Hirano A, Zimmerman HM. Some new pathological findings in the central myelinated axon. Neuropathol Exp Neurol 1971;30:63-7.

18 Morris JH, Hudson JR, Weddell A. A study of degeneration and regeneration in the divided rat sciatic nerve based on electron microscopy III. Changes in the axons of the proximal stump. Zeitschrift für Zellforschung und Microscopischie Anatomic 1972;124:131-64.

19 Jacobs JM, Cavanagh JB Aggregations of filaments in Schwann cells of spinal roots of the normal rat. $\mathcal{F}$ Neurocytol 1973;1:161-7.

20 Spencer PS, Thomas PK. Ultrastructural studies of the dying back process II the sequestration and removal by Schwann cells and oligodendrocytes of organelles from normal and diseased axons. F Neurocytol 1974;3:763-83.

21 Cavanagh JB, Gysbers MF. Ultrastructural changes in axons caused by acrylamide above a nerve ligature. Neuropathol Appl Neurobiol 1981;7:315-26.

22 Nolan CC, Brown AW. Reversible neuronal damage in hippocampal pyramidal cells with triethyllead: the role of pocampal pyramidal cells with triethyllead: the role of
astrocytes. Neuropathol Appl Neuriobiol 1989;15:441-58.

23 Cavanagh JB, Nolan CC, Brown AW. Glial cell intrusions actively remove detritus due to toxic chemicals from within nerve cells. Neurotoxicol 1990;11:1-12.

24 Nolan CC, Brown AW. Reversible neuronal damage in hippocampal pyramidal cells with triethyllead: the role of astrocytes. Neuropathol Appl Neuriobiol 1989;15:441-58.

25 Tate-Ostroff B, Majocha RE, Marotta CA. Identification of cellular and extracellular sites of amyloid precursor protein extracytoplasmic domain in normal and Alzheimer disease brains. Proc Natl Acad Sci USA 1989;86:745-9.

26 Iwaki T, Hamada Y, Tateishi J. Advanced glycosylation endproducts and heat-shock proteins accumulate in the products and heat-shock proteins accumulate in the corpora-amylacea of the glia. Pathol Int 1996;46;757-63.

27 Jackson MC, Scollard DM, Mack RJ, et al. Localization of a novel pathway for the liberation of GABA in the human CNS. Brain Res Bull 1994;33:379-85.

28 Martin JE, Mather K, Swash M, et al. Heat shock protein expression in corpora amylacea in the central nervous system: clue to their origin. Neuropathol Appl Neurobiol 1991;17:113-19.

29 Cisse S, Schipper HM. Experimental induction of corpora amylacea-like inclusions in rat astroglia. Neuropathol Appl Neurobiol 1995;21:423-31.

30 Tamura S, Takahashi M, Kawamura S, et al. Basophilic degeneration of the myocardium: histological, immunohistochemical and immuno-electronmicroscopic studies. Histopathology 1995;26:501-8. 